\title{
SOME ASPECTS OF THE DISCRIMINATION OF MIGRANTS IN LABOR RELATIONS
}

\author{
Marija Kojchevska ${ }^{1}$ \\ Marko Andonov ${ }^{2}$ \\ Kate Trajkova ${ }^{3}$
}

DOI: https://doi.org/10.31410/ERAZ.2019.191

\begin{abstract}
Discrimination as a global phenomenon is becoming more and more present in all areas of social life. It is a phenomenon that is relatively difficult to define and more difficult to quantify. On the other hand, the labor relations have dominant importance for quality existence of the citizens and the society as a whole. Moreover, when the aforementioned aspects are considering and analyze through the prism of migration, we face with greater challenge.

In this sense, the paper will be focused on studying and analyzing the most important aspects of discrimination of migrants in labor relations. Thus, an overview of the notion and the legal framework of discrimination will be given first. At the same time, the concept of free access to the labor market will be processed, in order to determine the selective approach of the companies in the employment process. At the same time, the lack of intercultural knowledge by the employers will be emphasized, with a special focus on comparing experiences from several countries. In this context, the situation with migration will be positioned worldwide.

The paper will give a concrete contribution to clarifying the future of the EU's economic migration policy, which will need to be well based on the new reality of the regional and global context of the labor market. The calls for new approaches to the labor market policies that consider cross-border mobility, promotes more inclusive employment, increases productivity and labor market participation among all working-age groups, as well as enhances the contribution of migration for growth and competitiveness of the global economy.
\end{abstract}

Keywords: discrimination, migrants, labor relations.

\section{INTRODUCTION}

$\mathrm{H}^{\mathrm{u}}$ uman rights contained in international and regional instruments have inevitably succeeded in affecting all areas in the process of making important decisions and migration is no exception. However, migrants continue to be disproportionally affected by human rights violations. Mainly, this is a consequence of their status as non-nationals of the country they live, but this may also be a result of their frequent risky trips, during and after their return to their home county.

Contrary to general assumptions, migrants who are documented are not immune to the abuse of their human rights, but migrants who are in irregular situations are generally subject to a higher level of vulnerability, while encountering major obstacles to access the protection of which they have right to. Therefore, it is of particular importance to emphasize that human rights apply to all migrants, regardless of their migration status.

1 School of Law, “University American College Skopje”, Bul. Treta Makedonska Brigada No. 60, 1000 Skopje, Republic of N. Macedonia

2 School of Law, “University American College Skopje”, Bul. Treta Makedonska Brigada No. 60, 1000 Skopje, Republic of N. Macedonia

3 School of Law, "University American College Skopje”, Bul. Treta Makedonska Brigada No. 60, 1000 Skopje, Republic of N. Macedonia 
Migration is a complex and politically sensitive subject that is difficult to define and measure. In Europe, there is an increase of migration, as well as significant changes in terms of the model and the type of migration. Such changes are very likely to continue. The reasons for migration are diverse and difficult to sort. Migration is a major factor for population change and it is essential for the structure of the labor market.

At the same time, migration is a global phenomenon that has an impact on the lives of the majority of people. About 258 million people are qualified as international migrants and in our ever-growing interconnected world, millions more are affected by family ties, economical exchanges and cultural ties. Migration, among other things, is a powerful driver for sustainable development for the migrants themselves and their communities in the country of origin, transit and destination.

Migrants partake about 3 percent of the world's population, but they actually generate more than 9 percent of the global GDP.

They often create meaningful benefits for their new communities, in form of skills, labor strength, investment and cultural diversity. Additionally, migrants play a role in improving the lives of communities in their countries of origin, through the transfer of skills and financial resources, which contribute to better development outcomes.

However, if migration is inadequately managed, it may have a negative impact on the development, with migrants being at risk and the communities would face too many problems and pressures.

In some cases, discriminatory trends have recently deteriorated from hostile political discourse, which hasn't overlooked the possibility of risk of rejection and expulsion of migrant workers.

Hence, there is a need for quick and comprehensive responses to the emerging trends that can harm ongoing and future efforts in securing an equal opportunity for employment. With growing economic uncertainty for the entire population, minorities and foreigners or foreign workers risk becoming scapegoats.

\section{LEGAL FRAMEWORK OF DISCRIMINATION}

Discrimination stems from prejudices and stereotypes that are developed most often by the majority. It is an unequal treatment, that is, making differences between people, either positive or negative, and based on certain personal characteristics, that is, discriminatory basis, which leads to exclusion, limitation or giving priority to a particular person/group.

According to the definition of the European Court of Human Rights, the basis for discrimination is "a personal characteristic (status) according to which persons or groups of persons differ from one another."

Despite the enormous progress at the international level in strengthening the legal protection of individuals and groups of persons against discrimination, reports from several parts of the world confirm that discriminatory acts and practices are everything but a memory from the past.

Following the ban on discrimination based on race, sex, language and religion in the Charter of the United Nations, the adoption of the Universal Declaration of Human Rights [1], together 
with the Convention on the Prevention and Punishment of the Crime of Genocide in 1948 [2], became the next important step in the legal consolidation of the principle of equality before the lad and the emergence of a ban on discrimination.

Article 1 of the Universal Declaration proclaims that: „All human beings are born free and equal in dignity and rights”, while under Article 2: „Everyone has the right to all the rights and freedoms set forth in this Declaration, regardless of the kind, such as race, colour, sex, language, religion, political or other opinion, national or social origin, property, birth or other status."

Regarding the right to equality, Article 7 of the Universal Declaration provides that: „Everyone is equal before the law and is entitled without any discrimination for equal protection of the law. Everyone has the right to equal protection against any discrimination contrary to this Declaration and against any incitement to such discrimination."

The European Convention on Human Rights [3] differs from other general human rights treaties by not having an independent prohibition of discrimination, but only a prohibition related to the enjoyment of the rights and freedoms guaranteed by the Convention and its protocols. This means that allegations of discrimination that are not related to the achievement of these rights and freedoms do not fall within the competence of the European Court of Human Rights. Article 14 reads as follows: „The enjoyment of the rights and freedoms set forth in this Convention shall be provided without discrimination on any ground such as sex, race, color, language, religion, political or other opinion, national or social origin, affiliation with a national minority, property, birth or other status."

It is interesting to note that the prohibition of discrimination in Article 14 includes ,association with a national minority", which cannot be construed as expressis verbis in Articles 2 (1) and 26 of the International Covenant on Civil and Political Rights, Article 1 of the American the Convention on Human Rights or Article 2 of the African Charter on Human and Peoples' Rights. However, the last provision, as seen above, uses the term ,ethnic group”, which has a more limited range of ,minority”.

However, the member states of the Council of Europe have taken important steps to overcome the above-mentioned mistakes in the Convention: on 4 November 2000, the fiftieth anniversary of the adoption of the Convention, they adopted Protocol No. 12 to the European Convention containing a general prohibition of discrimination.

„Within the ILO, as a specialized UN agency, the principle of equality and the prohibition of discrimination is provided for in the Convention on the Protection of the Rights of All Migrant Workers and Members of Their Families and the Convention against Discrimination in the Field of Employment and Labor Engagement since 1958. In accordance with the second, any form of different treatment, exclusion or privileged treatment based on race, color, sex, religion, political opinion, national or social origin, which aims to disrupt the equal opportunity or treatment in employment relationship or work engagement. However, unequal treatment regarding specific work based on certain employment conditions will not be treated as discrimination. Also, these principles are provided in the Equal Remuneration Convention, which provides equal compensation for the male and the female workers based on identical standards, without any gender discrimination. Within the ILO, the Convention on Vocational Rehabilitation and Employment of Persons with Disabilities was adopted in 1983, which provides equal treatment of persons with disabilities and the introduction of affirmative measures in accordance with which will enable effective equal treatment and which will not constitute discrimination versus other workers." [4] 


\section{FREE ACCESS TO THE LABOR MARKET}

"The lack of labor and skills [5] is expected to increase in the EU in the short and medium term as a result of demographic trends in labor reductions and structural changes in the distribution of occupations and the nature of skills in demand caused by a competitive global economic environment. After decades of growth, the decline in the working-age population in the EU began in 2013, according to Eurostat's demographic projections, which indicate a loss of over 2.5 million in the EU's working-age population in the decade 2010-2020 and a fourfold higher decline in the next decade. This will result in a 12 percent reduction in the working-age population in the EU by 2030. Concerning the composition of the skills of the EU workforce, there has been a significant increase in the past decades, largely due to the higher education of new entrants in the workforce compared to pensioners. However, a recent OECD analysis of the demography of education suggests that in the period 2010-2020, the share of highly educated workers among older retired cohorts will be significantly higher than in previous decades, leading to a much slower increase in the size of highly skilled workforce." [6]

In most EU Member States, labor migration systems are predominantly driven by demand, that is, the migration of workers from third countries is approved in response to the existence of a shortage of labor, which can be identified in various ways, among which the most common are labor market tests and weakness lists. As a general rule, in demand-based schemes, migrant workers are not allowed entry into the country without a job offer. On the other hand, workers who are ready to fill such deficiencies, and who cannot meet them by engaging a citizen or workforce of the EU, are expected to hire an employee who still lives abroad. These labor migration systems suggest that the employment contest between employers and employees would generally occur without a prior meeting between the concerned stakeholders. In this context, access to labor market information for employers and future migrants is crucial if international migration plays a role in responding to a lack of labor and skills.

\section{DISCRIMINATION AND LACK OF INTERCULTURAL KNOWLEDGE - COMPARATIVE APPROACH}

The lack of intercultural knowledge by employers can also lead to a relative weakness for migrants compared to natives in the recruitment process. Due to resource constraints and limited experience in the employment of people from abroad, SMEs appear to lack capacity (in terms of counseling and training) to address issues related to cultural diversity in the employment process. Certain behavior or dressing patterns during an interview, for example, if it is not fully in line with the country's standard practices, can be considered unprofessional. In addition, the cultural attitudes and preferences of the candidate for migration can be considered as a potential risk in terms of good interpersonal relationships with potential future colleagues and the cohesion of the work team. As a consequence, even when explicit discrimination against migrants is not in sight, implicit stereotypes and intercultural barriers can contribute to unfairness in the employment process, affecting the positivity of migrant employment results compared to natives with the same levels of qualifications and competencies.

The study on Germany showed that despite the introduction of the wider anti-discrimination law in 2006, discriminatory behavior against ethnic minorities still plays a role in disabling migrants' access to jobs at the same level as indigenous people. Findings of recent study trials for student internship applications have been noted [7], suggesting that if all other things are equal, 
candidates with a Turkish-sounding name, on average 14 percent, are less likely to receive an invitation for job interview than applicants who have a German-sounding name. This difference in rates of returns on call has been shown to be even greater in small and medium enterprises - 24 percent.

In spite of this, and in accordance with the public debate after the announcement of these results, the Federal Anti-Discrimination Agency launched an experiment with anonymous applications for work in Germany to examine their potential in the fight against discrimination in employment. This initiative was inspired by field experiments in other European countries, such as France, Sweden and the Netherlands.

The results of the German experiment are encouraging, since anonymous applications for work really seem to reduce discrimination in employment. Anonymous job applications can be practically implemented without excessive costs and lead to equal opportunities for minority groups of candidates - at least in the initial phase of the recruitment process. However, in the more advanced stages of the employment process - and, in particular, in the job interview - implicit discrimination and stereotyping [8] and taking into account cultural diversity can still result in a relative disadvantage for applicants of migrant background.

In Sweden, according to the Discrimination Law, which came into force in 2009, employers with 25 or more employees must have a plan of action against discrimination and conduct a payroll audit every 3 years. They can turn to the Ombudsman for Equality for guidance on how to comply with the law, and they are also offered the opportunity to participate in courses (such measures should be extended to smaller firms). A good practice that is in favor of improving awareness in the application of diversity in employment in Sweden consists of network meetings organized by the Ombudsman with trade unions and representatives of employers' associations. Lawyers and experts from this area are invited to participate, whose goal is to exchange experiences from work in cases of discrimination and to effective measures. [9]

Canada has an increasingly ethnically diverse population, due to the high levels of permanent migration. Given national concern over the decline in labor growth and the lack of some skilled professions, Canada's immigration policy is oriented towards attracting highly educated workers. How do economic migrants get information about job opportunities in their country of destination? What information on the labor market is available to employers who want to meet their work needs with migrant workers? These are crucial issues to respond to the implementation of the migration policy. The advantages of migration are numerous and, given the legal and informational barriers inherent in migrating abroad for employment, immigration systems that direct these processes and provide information to employers and migrant workers are of paramount importance.

Key features of the Canadian labor market include significant regional differences in employment opportunities through occupation and a reduction in workforce growth. The older workforce has several obvious implications for the future: greater pressure on Canadian health care, more pressure on public pensions, and most importantly more pressure on firms that sometimes struggle to meet the needs of new entrants and skilled workers. Indeed, the slower growth of the population and the older workforce means that many Canadian businesses must attract more workers capable of filling their needs from abroad. 
These two trends are accompanied by significant regional wage differences, large differences in production composition in 10 provinces in Canada and a steady urban-rural pay gap. Reducing population growth also means that, according to most estimates, migration will be responsible for the overall growth of Canada's net workforce in the coming years. [10]

The barriers to employment faced by migrants in Canada are more fundamental than the informative ones. The most common difficulties reported by migrants are the recognition of foreign experience, education and qualifications and language barriers. These factors make a greater contribution to any gaps in labor market outcomes for migrants than to difficulties in accessing information on the labor market. Additionally, an information barrier has been identified as an important factor: workers born overseas often have difficulty finding out about job opportunities in their area due to lack of personal contacts. [11]

\section{CONCLUSION}

Removing discrimination as a contributor to layoffs is very difficult. Migrant workers are concentrated in sectors sensitive to the business cycle, often with temporary or insecure work contracts and, during an economic crisis, employment rates are declining rapidly in these sectors.

Paraphrasing Cholewinski, the feminization of migrant workforce and increased reliance on countries on temporary workers are not adequately reflected in ILO or ICMW instruments.

Another major obstacle is the chronic reluctance of states to comply with legally binding, multilateral instruments that regulate international labor migration and the protection of the rights of migrant workers. At the same time, it is obvious that the overstaffing of employers over workers remains a problem. The growth of irregular migration is not general, but limited to specific constraints, with the United States forming a large part of them.

In the short term, instead of the new standards, genius could best invest in aligning the road to regional and national adoption and implementation of existing standards and capacity building in trade unions and enterprises.

Greater and closer cooperation could help in the adoption of standards and in the continuation of their implementation. This should include cooperation between countries of origin and destination countries, and in particular between competing economies.

Setting up human rights standards is an important activity in itself. In addition, we urgently need a better, empirically grounded understanding of their effects. This can only be obtained with significant data and appropriate statistical techniques. Introduction of standards or their implementation should be the subject of studies. Academic research literature in recent years produces many useful insights into the processes of discrimination.

In this context, the future of the EU's economic migration policy should be well based on the new reality of the regional and global context of the labor market. This calls for new approaches to labor market policies that take into account cross-border mobility, promotes more inclusive employment, increases productivity and labor market participation among all working-age groups, and enhances the contribution of migration to growth and competitiveness. 


\section{REFERENCES}

[1] The Universal Declaration of Human Rights, 1948.

[2] Convention for the Prevention and Punishment of the Crime of Genocide, 1948.

[3] European Convention on Human Rights, 1950.

[4] Elena J. Brezoska, Equality as a fundamental right - with particular reference to the practice of the European Court of Human Rights in relation to protection against discrimination, Foundation Open Society Institute - Macedonia, 2011, p.31.

[5] A labor shortage occurs when there are usually very few people applying for vacancies, including entry-level positions or those who do not require a particular type of skills. Lack of skill occurs when there are shortages of candidates with the required education, experience or skills for applying for a job. Often, labor shortages and skills coexist.

[6] Maria V. Desiderio, Improving access to labour market information for migrants and employers, IOM, 2013.

[7] L. Kaas and C. Manger, German Economic Review, vol. 13, issue 1, 2012.

[8] Dan-Olof Rooth, Implicit Discrimination in Hiring: Real World Evidence, Paper No. 2764, 2007.

[9] Maria V. Desiderio, Improving access to labour market information for migrants and employers, IOM, 2013.

[10] G. Picot and A. Sweetman, Making it in Canada - Immigration Outcomes and Policies, No. 29, 2012.

[11] G. Schellenberg and H. Maheux, Immigrants' perspectives on their first four years in Can$a d a$, Catalogue No. 11-008, 2007. 